\title{
Stroke and Cardiovascular Disease among Women
}

\author{
Hengameh Hosseini \\ Certificate Program in Long-Term Care, School of Public Affairs, Penn State University, Middletown, USA \\ Email: huh19@psu.edu
}

Received 12 October 2015; accepted 28 December 2015; published 31 December 2015

Copyright (C 2015 by author and Scientific Research Publishing Inc.

This work is licensed under the Creative Commons Attribution International License (CC BY). http://creativecommons.org/licenses/by/4.0/

c) (i) Open Access

\begin{abstract}
Stroke falls under the umbrella of cardiovascular disease (CVD), which is the number one killer of Americans. CVD, including stroke and heart disease, takes about 267,000 women's lives every year [1]. In the present study, a health risk assessment of a population of women residing in Northeastern Pennsylvania was conducted to provide an estimate of vulnerability to stroke on the basis of medical history, genetic predisposition, and other lifestyle factors. Using the Health Belief model of Rosenstock, Strecher, and Becker [2] and the stage model of Prochaska, Diflemente, and Norcross [3], a health promotion plan was developed to address the needs of that population. An evaluation of risks that can and cannot be modified is developed to help people understand the basic lifestyle changes that could be made to prevent CVD, which includes stroke. An action plan was developed to lower the risk of stroke among women based on their individual needs and to raise awareness throughout the United States. Individuals should take the essential precautions for their personal cases. This will substantially lower the risk of CVD, especially stroke, among women.
\end{abstract}

\section{Keywords}

Cardiovascular Disease, Stroke among Women, Risk Factors, Life Style, Health Belief Model

\section{Introduction}

It is a well-known fact that cardiovascular disease (CVD), which includes stroke, is the number one killer in the United States. For many years, it was assumed that CVD, and thus stroke, mainly affected men. However, we now know that CVD, which includes heart disease and hypertension as well as stroke, also affects a substantial number of women. According to an American Heart Association fact sheet, "CVD caused one death per minute among females [4]. The good news is that women and men can substantially reduce many of their risk factors 
for stroke and heart disease with simple life style changes.

In this health risk appraisal, the intent is to identify and study the potential or real risk of stroke in a population of women. This kind of risk appraisal will provide an estimate of the type of health threats- here, stroketo which individual members of this population (i.e., women) might be vulnerable due to genetic predisposition, medical history, and other factors that reflect the lifestyle of the individual.

We have chosen to study forty-nine women who were selected randomly by the Wyoming Valley Health Care System in Wilkes-Barre, Pennsylvania. These women were all participants in the "Stroke Alert: A Stroke Risk Assessment Campaign Protocol” program of the American Stroke Association, which is a division of American Heart Association (The Stroke Alert Campaign is an education initiative designed to evaluate people's risk of stroke and provide appropriate heart counseling and education). We were given permission by the Wyoming Valley Health Care System to access and study the information collected on those women using American Stroke Association's "stroke risk assessment" forms. To study the test group, we will utilize the model developed by Heller, Tunstall, and Rose [5]. Then, based on my analysis of the population and individual subjects, we will develop a health promotion plan to address the particular needs of the population under study. In developing this plan, we will utilize the Health Belief model developed by Rosenstock, Strecher, and Becker [2], as well the stages model of Prochaska, Diflemente, and Norcross [3]. Following these introductory remarks, we will discuss various risk factors for stroke.

\section{Risk of Stroke and Its Causes}

The American Heart Association has identified several factors that increase the risk of heart disease and stroke. Obviously, the more risk factors a woman has, the greater her risk of stroke or heart attacks. There exist two types of risk factors: those that women (or men) cannot control, and those that they can modify or treat (thus lowering their risk).

According to a publication of the American Heart Association [6], the following are the risk factors for heart disease and stroke that fall into the first category:

- Increasing age. As women grow older, their risk of heart disease and stroke begins to rise.

- Gender. Men have a greater risk of heart attack than women, and they have attacks earlier in life. However, according to the American Heart Association [7], the opposite is the case for stroke.

- Heredity. Both women and men are more likely to develop heart disease or stroke if their close blood relatives have had the diseases.

- Race. Both African-American women and men are more likely to die when they have strokes.

- Previous heart attacks and transient isocheim attacks (TIA). Women who have had a heart attack before are at higher risk of having a second heart attack. There is a 10 times more chance of having stroke if a person has had one or more TIA's [8].

The following are risk factors that can be modified, treated, or controlled by focusing on lifestyle habits and taking medicine, if needed:

- Tobacco. Smoking is a major cause of cardiovascular disease among women. Women who smoke have an increased risk of isocheim stroke and subarachnoid hemorrhage. Constant exposure to others' tobacco smoke at work or at home also increases the risk, even for nonsmokers.

- High blood cholesterol. High blood cholesterol increases the risk of stroke. According to AHA, studies show that women's cholesterol is higher than men's after the age of 44. Higher levels of LDL (low-density lipoprotein) cholesterol (the "bad" cholesterol) raise the risk of heart disease and heart attack.

- High blood pressure. According to AHA [6], it is the most important risk factor for stroke. Women are said to have an increased risk of developing high bold pressure if: they are obese, have a family history of high blood pressure, are pregnant, take certain types of birth control pills, or have reached menopause.

- Physical inactivity. Various studies have shown that lack of physical activity is a risk factor for heart disease and indirectly increases the risk of stroke. Studies have found that inactive people are almost twice as likely as active people to develop heart disease. The American Heart association recommends accumulating at least 30 minutes of physical activity on most days of the week [9].

- Obesity and overweight. According to AHA, if a person has too much fat, especially around the waist, he or she will be at a higher risk stroke [10].

- Diet. People that consume more saturated fats, trans fat, and cholesterol are at more risk of getting a stroke 
because of their high blood cholesterol levels.

- Diabetes mellitus. Compared to women without diabetes, women with diabetes have from two to six times the risk of having a stroke.

Are there any more risk factors that we should consider? American Heart Association mentions three more risk factors for stroke and heart disease among women: high triglyceride levels, excessive alcohol intake, and drug misuse, drug abuse, individual response to stress, geographic and socioeconomic factors [6].

\section{Literature Review: CVD and Stroke}

Stroke is a cardiovascular disease because it is caused by a lack of blood flow to the brain from a blood clot, or bleeding in the brain from a broken blood vessel. In other words, without a certain blood supply, brain cells cannot get sufficient oxygen, and begin to die. According to the Centers for Disease Control and Prevention, CVD is still the biggest killer among men and women in the United States [1]. Further, according to American Heart Association [11], stroke is a leading cause of serious, long-term disability; an estimated 15 to 30 percent of stroke survivors are permanently disabled. The Centers for Disease Control and Prevention reports that in the United States, roughly 600,000 people die from heart disease every year [12]. As stated before, CVD is often thought to disproportionately affect the male members of the US population and the elderly. However, the dangers of CVD extend beyond men. According to some measures, CVD is worse for women. For example, according to the AHA Fact Sheet [7], 26 percent of women who have heart attacks die within one year, compared with 19 percent of men. Generally, the explanation accepted by many is that women tend to get heart disease about ten years later in life compared with men, and they are more likely to have coexisting, chronic conditions. However, according to the Fact Sheet, research also shows that women may not be diagnosed or treated as aggressively as men, and their symptoms may be very different from those of men who are having a heart attack [1]. New studies also indicate that men and women react to drugs prescribed for heart disease differently.

Interestingly enough, differences also exist in this regard in the US between white women and black women. According to the Fact Sheet, studies show that deaths due to CVD are much higher in black women than in white amount-almost 50\% higher [12]. But CVD disease mortality seems to be lower among Hispanic, Native American, and Asian/Pacific Islander women compared with white women.

As we have known for a while, to monitor the incidence of CVD among individuals, invasive procedures such as blood sampling are not always feasible because of cost factors [13]. As a result, less costly procedures might be desirable. One such self-administrated and feasible procedure is the Fat Intake scale, which was developed by Retzlaff and colleagues [14]. The method provides a reliable estimate of fat, saturated fat, caloric and cholesterol intake in the diet of the individual.

\section{Risk of Stroke in Pregnant Women}

There have been other studies that have presented pregnant women and their risk of stroke. According to Jessica Tate and Cheryl Bushnell from AHA [8], some instances that lead to pregnancy related stroke are "hypertension, diabetes, valvular heart disease, hypercoagulable disorders, sickle cell disease, lupus, abuse of tobacco and other substances, and migraines”. The study shows that women with hypertension during pregnancy are about 6 to 9 times more likely to have stroke than women without hypertension. The American Heart Association states that pregnancy related strokes are becoming increasingly common and have risen 54\% from 1994-95 to 2006-07 [8]. Even though women who are older are at more risk of getting a stroke, it is now proven that "pregnant and post-partum women aged 25 - 34 were hospitalized for stroke more often" [8]. Howard Le-Wine [15] states that about 1 in 12 women develop preeclampsia or other blood pressure problems during pregnancy that raises the blood pressure and increases the amount of protein in urine. Now a day's more and more women are pursuing their careers and have chosen to start a family later in life. This is actually going to be putting more women at risk of stroke because women are more prone to having a stroke later in life.

\section{Methods}

The population examined in this study consists of a sample of 49 adults, all of whom resided in the Luzerne County, Pennsylvania at the time of data collection. Each of these 49 individuals was participating in American Stroke Association's Stroke Alert: A Stroke Risk Assessment Campaign Protocol [10].” 


\subsection{Risk Assessment Process and Its Steps}

As of 2005, the American Stroke Association's Stroke Risk Assessment campaign [10] consisted of the following 12 steps, which seem to have been amended in 2014 as depicted in Table 1 below.

- Explain the risk factors and signs of stroke to the subject.

- Educate the individual about the risk factors of the person and identify the risks that can be improved through lifestyle behavior modification.

- Tell the individual her blood pressure and pulse numbers and explain where the screening results fall according to national recommendations.

- State that a single blood pressure measurement does not constitute a diagnosis.

- Listen to the carotid artery to detect bruits (skip this step if noise level is not conducive to conducting this test).

- Give cholesterol and glucose measurement results. However, these are not a mandatory part of the Stroke Alert Campaign. If they are not measured, check "Not done" on the relevant portion of the assessment form.

- Refer participates as per guidelines and protocols and complete the action plan portion of the assessment form.

- Document advice given on the form.

- Reference sudden signs of stroke and the need to call 9-1-1 located on the bottom of the assessment form.

- Provide American Stoke Association educational materials based on participant's individual action plan.

- Answer any questions.

- Provide participants with two carbon copies of the form. Return the top copy of the form to the hospital, and the yellow copy to the ASA.

\subsection{Stroke Risk Assessment and Form Completion}

As stated before, the number of physiological and environmental risk factors has been identified for stroke; controlling these risks via lifestyle changes and medical treatment may offer substantial stroke prevention and risk

Table 1. Seven immediate action priorities for 2014 and beyond.

\begin{tabular}{|c|c|c|}
\hline Priority & Focus & Action Needed \\
\hline $\begin{array}{c}\text { Effective } \\
\text { communication }\end{array}$ & $\begin{array}{l}\text { Prevention and } \\
\text { public health }\end{array}$ & $\begin{array}{l}\text { Communicate to legislators, policymakers, and the public at large } \\
\text { the nation's vital stake in sustaining and building upon the prevention and } \\
\text { public health provisions in the Affordable Care Act, e.g., } \\
\text { the National Prevention Council, Prevention and Public Health Fund, and others. }\end{array}$ \\
\hline $\begin{array}{l}\text { Strategic leadership, } \\
\text { partnerships, and } \\
\text { organization }\end{array}$ & $\begin{array}{l}\text { Public health-healthcare } \\
\text { collaboration and } \\
\text { integration }\end{array}$ & $\begin{array}{l}\text { Integrate public health and health care into a public health system } \\
\text { effective in supporting community-level prevention policies } \\
\text { and programs, e.g., the Million Hearts Initiative. }\end{array}$ \\
\hline Taking action & $\begin{array}{l}\text { Cardiovascular } \\
\text { health and health } \\
\quad \text { equity }\end{array}$ & $\begin{array}{l}\text { Develop, advocate, and implement policies, programs, and practices aimed } \\
\text { improve the nation's cardiovascular health in terms of the Healthy People } 2020 \\
\text { objectives and AHA metrics-addressing tobacco use, overweight/obesity, activity, } \\
\text { healthy diet (including reduction in sodium and artificial trans fat intake), } \\
\text { blood pressure, cholesterol, and fasting plasma glucose); and ensure that all } \\
\text { such actions reach everyone, especially those most vulnerable due to } \\
\text { unfavorable social and environmental conditions. }\end{array}$ \\
\hline Building capacity & $\begin{array}{l}\text { Prevention } \\
\text { workforce }\end{array}$ & $\begin{array}{l}\text { Make full use of resources for education and training of the prevention } \\
\text { workforce at local, state, national, and global levels. }\end{array}$ \\
\hline $\begin{array}{l}\text { Evaluating } \\
\text { impact }\end{array}$ & $\begin{array}{l}\text { Monitoring } \\
\text { cardiovascular } \\
\text { health }\end{array}$ & $\begin{array}{l}\text { Advocate for a comprehensive, robust and timely system of monitoring } \\
\text { cardiovascular events (heart attacks, stroke, heart failure) and cardiovascular } \\
\text { health metrics for the US population, including full adoption of the } \\
\text { "developmental” heart disease and stroke objectives of Healthy People } 2020 \text {. }\end{array}$ \\
\hline Advancing policy & $\begin{array}{l}\text { Research on critical } \\
\text { questions to advance } \\
\text { policy and practice }\end{array}$ & $\begin{array}{l}\text { Pursue needed implementation and dissemination science and health } \\
\text { economics research, including needed education and training for this research, } \\
\text { in support of health policy development, implementation, and dissemination. }\end{array}$ \\
\hline $\begin{array}{l}\text { Engaging in } \\
\text { regional and global } \\
\text { collaboration }\end{array}$ & $\begin{array}{l}\text { Initiatives linking } \\
\text { CVD and NCD } \\
\text { prevention }\end{array}$ & $\begin{array}{l}\text { Undertake collaborations in major regional and global cardiovascular } \\
\text { health and NCD initiatives, in the interest of improving cardiovascular } \\
\text { health and reducing the burden of NCDs in the United States and globally. }\end{array}$ \\
\hline
\end{tabular}


reduction benefits [16]. As a result, it is suggested that clinicians conducting these stroke risk assessments review all stroke factors for participants and give recommendations using the Action Plan section of the Assessment Form (and check appropriate boxes) [10].

\subsection{Demographic Data Collection}

The Stroke Risk Assessment Form [6] asks participants various questions that are demographic in nature. These include questions about age, gender, race/ethnicity, height and weight.

Following the demographic questions (and a mention of uncontrollable risk factors), the form contains questions about both the subject and the subject's family, concerning the following: medical history, previous stroke, previous mini-stroke (TIA), carotid artery disease, (present or past) high blood pressure, previous heart attacks, heart disease, arterial fibrillation, heart surgery, diabetes, (current or past) high blood cholesterol, whether the person is or was a smoker (and if so, what the average number of packs a day is/was), and alcohol consumption (and what the average number of drinks per day/month is, if any).

The next set of questions supplies the following information about the individual (women): blood pressure, with fields for systolic and diastolic measures, and the average of the two measures; pulse rate, with a box to check off whether it is regular or irregular; carotid bruits, with boxes to check for not detected, right, left, both and not done; cholesterol, with fields for total, HDL, LDL, and a box for not done; and glucose, with fields for $\mathrm{mg} / \mathrm{dl}$, and not done.

\subsection{The Health Belief Model: A Conceptual Framework}

Many writers have utilized the Health Belief Model, borrowed from the behavioral sciences, in an attempt to explain the health behavior of individuals. The Health Belief Model, which was modified by Becker in 1986, "is a model for addressing problem behaviors that evoke health concerns...the health belief model proposes that a person's health-related behavior depends on the person's perception of four critical areas: 1) the severity of a potential illness, 2) the person's susceptibility to that illness, 3) the benefits of taking a preventive action, and 4) the barriers to taking that action. The model considers factors like perceived susceptibility to illness, the perceived severity of the illness, the perceived costs versus the benefits of taking actions to prevent such illnesses, and considers benefits and barriers to taking actions, it is very comprehensive. The model can be utilized in explaining the behavior of the participants in our study. However, it can be used to describe other health related behaviors as well. For example, McIntosh and colleagues [17] argued that the Health Belief Model, in addition to being useful for explaining why individuals choose to make dietary changes, can also be used for providing excellent information for the proper construction and implementation of nutritional education programs.

The handout "Foundations of Applying Theory in Health Promotion Practice [2]" discusses the 1998 application of the HBM model to the challenges of changing habitual unhealthy behaviors, such as smoking and overeating (p. 19). We can apply the HBM model to the risks of stroke for women who participated in the Stroke Alert campaign indicated above (Table 1). While the application of the Health Belief Model by Rosenstock, Strecher, and Becker [2] is based on the perceptions of the individual about the risks of condition, my application of it will be based on the views of the clinicians doing the testing (based on the tests done on and observations made of the participants).

\section{Results}

Our study included 49 Caucasian women, whose ages ranged between 33 to 89 years, heights between 4'10" and 5'7", and weights between 100 and 290 pounds.

In terms of the risk factors (besides race, gender), the 49 individual women responded to the risk factors indicated in the Stroke Assessment Form as follows: (Table 2)

- Two women had previous strokes.

- One had a mini-stroke (TIA) before.

- No one had carotid artery disease.

- Twenty-two had or still have high blood pressure.

- Four had previous heart attacks.

- Nine have had heart disease. 
Table 2. Health belief model: The risks of stroke.

\begin{tabular}{|c|c|c|}
\hline Concept & Definition & Application \\
\hline Susceptibility & $\begin{array}{l}\text { Clinician's views of a participant's } \\
\text { chances of having a stroke }\end{array}$ & $\begin{array}{l}\text { Define population at risk } \\
\text { and their risk levels. Personalize risk } \\
\text { of stroke based on medical conditions, } \\
\text { weight, habits, and lifestyle. }\end{array}$ \\
\hline Perceived severity of stroke risk & $\begin{array}{l}\text { Clinician's opinion of how serious } \\
\text { the risk of stroke is }\end{array}$ & $\begin{array}{l}\text { Specify the consequences, risks, } \\
\text { and the possibility of stroke }\end{array}$ \\
\hline Benefits of action plan predicted & $\begin{array}{l}\text { Clinician's opinion of the efficacy of the } \\
\text { advised action to reduce seriousness of stroke }\end{array}$ & $\begin{array}{l}\text { Define actions to be taken by the participant: } \\
\text { how, when, where. Clarify the positive } \\
\text { effect taking these actions are expected to have. }\end{array}$ \\
\hline Barriers to action plan & $\begin{array}{l}\text { Clinician's opinion of tangible and } \\
\text { psychological costs of the advised action plan }\end{array}$ & $\begin{array}{l}\text { Identify and reduce these barriers through } \\
\text { reassurance incentives and assistance }\end{array}$ \\
\hline Cues to action & $\begin{array}{l}\text { Strategies to activate readiness to } \\
\text { follow the action plan }\end{array}$ & $\begin{array}{l}\text { Provide information, promote awareness, } \\
\text { and provide reminders }\end{array}$ \\
\hline Self-efficacy & $\begin{array}{l}\text { Clinician's confidence in the ability } \\
\text { of the participant to follow the action plan }\end{array}$ & $\begin{array}{l}\text { Provide training and guidance in doing } \\
\text { what is prescribed in action plan }\end{array}$ \\
\hline
\end{tabular}

- Three have had arterial fibrillation.

- Three had surgery before.

- Eight have had diabetes.

- Twenty-two have had high blood cholesterol.

- Five consume alcohol.

Of course, some women had multiple risk factors. Also, for each question, they were asked to respond in terms of themselves and their family. In various situations a risk existed because of a family history of stroke, heart attack, blood pressure, etc., and not the woman's own medical history. In other situations the opposite was the case. In a few cases, the woman was at risk because of her history and her family history.

To respond to the second set of questions in the Stroke Assessment Form, clinicians measured the following:

1) Blood pressure: systolic, diastolic, and the average of these.

2) Pulse rate measurement: regular or irregular.

3) Carotid bruits: not detected, right, left, both, and not done.

4) Cholesterol: total, HDL, LDL; clinicians also had the choice to list "not done".

5) Glucose level in terms of $\mathrm{mg} / \mathrm{dl}$; again, clinicians had the option to list "not done".

"Results and classification" is the next section in the Stroke Risk Assessment Form. Here, blood pressure levels classified. Normal systolic is considered to be less than $120 \mathrm{~mm} \mathrm{Hg}$, and normal diastolic pressure is less than $80 \mathrm{~mm} \mathrm{Hg}$. For systolic blood pressure, prehypertension is classified as 120 to $139 \mathrm{~mm} \mathrm{Hg}$, while diastolic prehypertension is 80 to $89 \mathrm{~mm} \mathrm{Hg}$. Hypertension is further grouped into stages one and two. For systolic, stage one ranges between 140 and 159, while stage two is 160 and higher. For diastolic, stage one ranges from 90 to 99 , and stage is 100 or higher.

A results classification is also given for cholesterol. For total cholesterol level, desirable is said to be less than $200 \mathrm{mg} / \mathrm{dl}$, borderline high is said to be between 200 and $239 \mathrm{mg} / \mathrm{dl}$, and high is said to be $240 \mathrm{mg} / \mathrm{dl}$ or more. For LDL, optimal levels are less than $100 \mathrm{mg} / \mathrm{dl}$, near/above optimal is said to be between 100 and $129 \mathrm{mg} / \mathrm{dl}$, borderline high is said to be between 130 and $159 \mathrm{mg} / \mathrm{dl}$, high is said to be between 160 and $189 \mathrm{mg} / \mathrm{dl}$, and very high is said to be $190 \mathrm{mg} / \mathrm{dl}$ and above. For HDL cholesterol levels, low is said to be less than $40 \mathrm{mg} / \mathrm{dl}$, and high (which lowers CVD risk) it is said to be $60 \mathrm{mg} / \mathrm{dl}$ or more.

\section{Action Plan}

Based on the above questions about stroke risk factors and measurements of these risk factors, an action plan is needed to lower women's risk of stroke. This action plan should consist of advice to each woman based on her individual risk factors and specific circumstance.

First, each woman with any risk factor should be advised to see her doctor for checking blood pressure, pulse, carotid bruit, cholesterol, glucose, and whatever is necessary, as determined on a case-by-case basis. Depending upon the number of risk factors present and their severity, the timeframe in which a physician should be seen 
will vary.

The subjects in our study should also be advised to review the above-mentioned information about risk factors with their physicians. In reviewing these data, women with one or more of the above risk factors should also consider adopting an exercise program, quitting smoking, losing weight if they are obese or overweight, having blood cholesterol checked regularly, and reducing their alcohol intake if they drink (excessively). In addition, women with risks of stroke should be advised to call for help (toll-free at 1-888-4-stroke, an ASA hotline) if they have a non-emergency problem. In more severe circumstances, women with risk factors should call 9-1-1.

\section{Conclusion}

The results of this study, aligning with previous research, show that health risks can be modified through simple lifestyle changes that will only improve the overall well-being of individuals. Women residing in Pennsylvania, participating in the American Heart Association Stroke Risk Assessment were included in this study. It was suggested that an action plan be developed by medical professionals and disseminated to those at risk for CVD and stroke. It is of utmost importance to take the necessary precautions to minimize risk factors. There is a continuum of risk among women that requires careful appraisal by medical professionals. Physicians can assess the chance that each woman has for having stroke and stroke or other vascular diseases according to risk prediction information known to them, and can optimize medical and life style studies of prevention. However, while medical profession can play a significant role in mitigating the risk of stroke and other cardiovascular diseases among women, it is very important that all women recognize the important role that they themselves can and should play in preventing those types of diseases by following a healthy life style that also includes exercise.

\section{References}

[1] Heart Disease Facts (2014) Centers for Disease Control and Prevention. http://www.cdc.gov/heartdisease/facts.htm

[2] Rosenstock, I.M., Strecher, V.J. and Becker, M.H. (1998) Social Learning Theory and the Health Belief Model. Health Education Quarterly, 15, 175-183. http://dx.doi.org/10.1177/109019818801500203

[3] Prochaska, J.O., DiClemente, C.C. and Norcross, J.C. (1992) In Search of How People Change: Applications to Addictive Behaviors. American Psychologist, 47, 1102-1114. http://dx.doi.org/10.1037/0003-066X.47.9.1102

[4] Women and Heart Disease Fact Sheet (2012) Centers for Disease Control and Prevention. http://www.cdc.gov/dhdsp/data statistics/fact sheets/fs women heart.htm

[5] Heller, R.F., Tunstall, P. and Rose, M. (1981) A Simple Method of Assessing the Effect of Dietary Advice to Reduce Plasma Cholesterol. Preventive Medicine, 10, 364-370. http://dx.doi.org/10.1016/0091-7435(81)90025-6

[6] American Heart Association (2002) Risk Factors and Coronary Heart Disease. American Heart Association Scientific Position, Living and Learning. http://www.americanheart.org/presenter.Jhm1?Identifier=4726

[7] Go, A., Mozaffarian, D., Roger, V., Benjamin, E., Berry, J. and Borden, W., On Behalf of the American Heart Association Statistics Committee and Stroke Statistics Subcommittee (2013) Heart Disease and Stroke Statistics-2013 Update. A Report from the American Heart Association. Circulation, 127, E6-E245. http://dx.doi.org/10.1161/CIR.0b013e31828124ad

[8] American Heart Association (2011) Rate of Stroke Increasing among Women during, Soon after Pregnancy. ScienceDaily. www.sciencedaily.com/releases/2011/07/110728162624.htm

[9] American Stroke Association (1993) Advocating Health Care: Reducing Your Risk Factors. Heart \& Stroke Facts Statistics of the American Heart Association, 3rd Edition, ASA Publications, Washington DC.

[10] American Stroke Association (2005) Stroke Alert: A Stroke Risk Assessment Campaign Protocol. Stroke Resources. http://www.strokeassociation.org/presenter.jhtml?identifier=3013970

[11] Turner, M.B., Neumar, R.W., Nichol, G., Pandey, D.K., Woo, D., Wong, N.D., et al. (2014) Executive Summary: Heart Disease and Stroke Statistics-2014 Update: A Report from the American Heart Association. Circulation, 129, 399-410. http://dx.doi.org/10.1161/01.cir.0000442015.53336.12

[12] Heart Disease Facts (2015) http://www.theheartfoundation.org/heart-disease-facts/heart-disease-statistics/

[13] Le Wine, H. (2014) New Guidelines Aim to Help Women Prevent Stroke-Harvard Health Blog. Harvard Health Blog RSS. http://www.health.harvard.edu/blog/new-guidelines-aim-to-help-women-prevent-stroke-201402077029

[14] Retzlaff, B.M., Dowdy, A.A., Walden, C.E., Bovbjerg, V.E. and Knopp, R.H. (1997) The Northwest Lipid Research Clinic Fat Intake Scale: Validation and Reliability. American Journal of Public Health, 87, 181-185. http://dx.doi.org/10.2105/AJPH.87.2.181 
[15] Lauer, M.S. and Fontanarosa, P.B. (2001) Updated Guidelines for Cholesterol Management. Journal of the American Medical Association, 285, 2508-2509. http://dx.doi.org/10.1001/jama.285.19.2508

[16] Labarthe, D., Grover, B., Galloway, J., Gordon, L., Moffatt, S., Pearson, T. and Sidney, S. (2014) The Public Health Action Plan to Prevent Heart Disease and Stroke: Ten-Year Update. National Forum for Heart Disease and Stroke Prevention. http://nationalforum.org/actionplan

[17] McIntosh, W.A., Kaplan, H.B. and Kubena, K.S. (1996) Blood Lipids, Cardiovascular Fitness, Obesity, and Blood Pressure: The Presence of Potential Coronary Heart Disease Factors in Adolescents. Journal of the American Dietetic Association, 96, 238-242. http://dx.doi.org/10.1016/S0002-8223(96)00073-9 